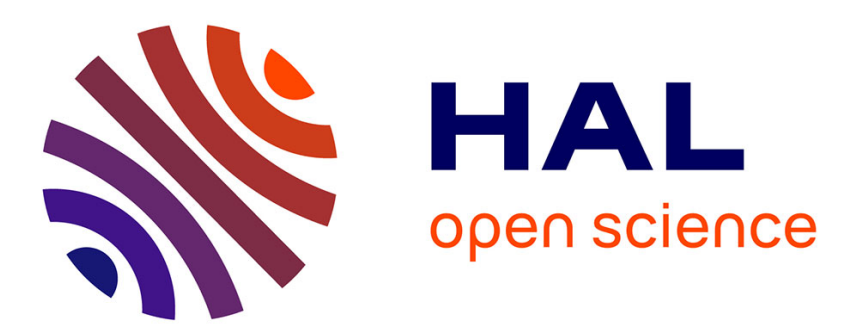

\title{
The unfolding of the verbal temporal system in French children's speech between 18 and 36 months
}

Christophe Parisse, Aliyah Morgenstern

\section{To cite this version:}

Christophe Parisse, Aliyah Morgenstern. The unfolding of the verbal temporal system in French children's speech between 18 and 36 months. Journal of French Language Studies, 2012, 22 (01), pp.95-114. 10.1017/S0959269511000603 . halshs-00495627v2

\section{HAL Id: halshs-00495627 https://shs.hal.science/halshs-00495627v2}

Submitted on 25 Jan 2012

HAL is a multi-disciplinary open access archive for the deposit and dissemination of scientific research documents, whether they are published or not. The documents may come from teaching and research institutions in France or abroad, or from public or private research centers.
L'archive ouverte pluridisciplinaire HAL, est destinée au dépôt et à la diffusion de documents scientifiques de niveau recherche, publiés ou non, émanant des établissements d'enseignement et de recherche français ou étrangers, des laboratoires publics ou privés. 


\title{
The unfolding of the verbal temporal system
}

\section{in French children's speech between 18 and}

\section{6 months}

\author{
Christophe Parisse \\ MoDyCo, INSERM, CNRS, Université Paris Ouest Nanterre La \\ Défense \\ Aliyah Morgenstern \\ Université Sorbonne Nouvelle-Paris 3
}

\begin{abstract}
In this paper, our aim is to analyze the relationship between the development of verbal forms and verbal functions. We examine all verbal forms produced longitudinally by two French children in terms of their morphosyntactic marking of tense, aspect, mood and situation type, and compare them to their contextually interpreted meanings. We introduce the main issues relevant to the unfolding of the verbal temporal system in children's data. Our data consists in two longitudinal corpora of French speaking children aged $1 ; 06$ to $3 ; 01$. The paper focuses on: 1) the relationship between form and function within the verbal system in the earlier stage of development;2) the children's ability to mark a displacement between speech time and event time.
\end{abstract}

KEYWORDS: verbal constructions, French language acquisition, time, tense, form/function mapping 


\section{INTRODUCTION}

The development of verbal temporal morphology is a domain in which children's cognitive, communicative and language abilities are clearly intertwined. A number of cognitive prerequisites, particularly the need to remember or anticipate remote events, are essential. The specific semantic and morphosyntactic properties of the language being learned must also be taken into account. French is a language with relatively rich verbal morphology. However, in oral French a large number of forms are homophonous; two of the most frequent phonological forms - past participle and infinitive of the first group as in fermé (closed) / fermer (to close) are overwhelmingly represented. In our previous work, we have observed two main stages of development (Morgenstern et al., 2009):

1) Only a small subset of the large variety of forms available in French is initially used. Children produce forms that are frequent and salient in the input, using them even more frequently and systematically than the adults.

2) Later, a variety of forms appear, including forms that are infrequent in the input. Children start producing several inflections for the same verb.

In this paper, our aim is to analyze the relationship between the development of verbal forms and verbal functions. Can children express 
various aspects and temporal relations before they have learned to use the conventional grammatical verbal forms? To address this question, we will examine all utterances containing lexical verbal forms as they are produced longitudinally by two French children, focusing on their morphosyntactic marking of tense, mood and situation type, and compare these utterances with their contextually interpreted meanings. ${ }^{1}$

Section 1 introduces the main issues relevant to the unfolding of the verbal temporal system in children's longitudinal data. In Section 2, we present our French data, our coding system and our quantitative results. Finally, Section 3 focuses on two issues: 1) the relationship between form and function within the verbal system during the earlier stage of development; and 2) children's ability to mark a displacement between speech time and event time.

\section{MAIN ISSUES}

\subsection{The French tense system}

French morphology is traditionally considered to mark tense more than aspect. In English, the past tense refers to completed past events, and the present perfect refers to events with relevance to the present (Klein, 1992).

\footnotetext{
${ }^{1}$ This does not mean that references to the past and to the future are limited to utterances containing lexical verbal forms - especially for young children who do not yet master the full grammatical tools of their language. However, in this chapter, we focus on the development of the relationship between lexical verbal forms and functions, and do not address the issue of the development of reference to time in general
} 
In contrast, the French 'passé simple' (corresponding to the English past tense) has almost disappeared from spoken French, except for retellings and reformulations of a written narrative; thus the 'passé composé' corresponds to both past tense and present perfect in English. As a result, the verbal form gives no clues as to whether an utterance refers to a present result or to a past event or activity.

(1) Il a couru [he has run - (which explains why he is tired)]. Il a couru [he ran - (there was a marathon last week)].

We need the context (presented between brackets next to the translation above) - the situation, the previous utterances, the shared knowledge between the interlocutors - to know whether the 'passé composé' used in each example refers to a past event with an impact on the present situation or a past event disconnected from the present situation. This difference which could be called aspectual and described as 'perfective' in the first case, and 'aoristic' in the second case, is not formally marked on the verbal form since the same grammatical tense is used. This lack of an explicitly marked distinction poses an obvious challenge for acquisition.

Other grammatical tenses, such as the 'imparfait', the inflectional future and the conditional (present or past), seem to be more clearly marked as corresponding to more specific functions, and thus may represent less of a challenge during the course of language acquisition. 


\subsection{Acquiring the tense system}

Children's ability to include temporal reference in their productions is often reported as developing gradually and slowly (Bronckart and Sinclair, 1973; Ferreiro, 1971; Smith, 1980). Temporal markers can be considered as the expression of the relation between 'speech time' - the moment when the speech occurs -, 'event time' - the moment when the event referred to occurs - and 'reference time' - a moment that provides an anchoring point so that events can be located relative to one another- (Reichenbach, 1947). As shown by Weist et al. (1991), building on the work introduced by Smith (1980), children are first linguistically, semantically and cognitively limited to the immediate situation - the here and now. Speech time is identical for them to reference time and they don't refer to event times disconnected from the present time. Then they become capable of disconnecting from the present time and refer to event time (past and future), and finally they develop the capacity to change their reference point, from speech time to another time and locate events relative to a reference time.

The pace of acquisition is considered to be governed by a combination of factors, including syntactic, semantic and cognitive complexity, as well as the frequency of the forms in the input.

\subsubsection{Cognitive factors}

In order to speak about the past, children must have stable mental representations of events in memory. In order to speak about future events 
or activities, they need to be able to anticipate them.

According to followers of Piaget's developmental theory (Bronckart and Sinclair, 1973:108), 'verbal patterns are constructed in close connection to cognitive development'. Children's grammars undergo shifts at crucial stages of cognitive reorganization. Before the 'concrete operational stage' children are egocentric; they live in the here and now and speak predominantly in the present tense and about present objects, people and activities. They are unable to talk about time other than the present time.

The importance of cognitive factors has been demonstrated by naturalistic (Cromer, 1968) and experimental studies (Ferreiro, 1971). Bronckart and Sinclair (1973) observed that up to age six, children tend to use the 'passé composé' for events with endpoints and the 'présent simple' for events without clear endpoints. They interpret the different tenses as expressing aspectual rather than temporal distinctions. According to the authors, only later do children begin to use these to mark different temporal relations.

However, a number of scientists have analyzed spontaneous data and introduced facts to reconsider children's cognitive 'limitations' in their use of the temporal system. Halliday (1975) showed that his son tried to narrate events in the past at 1;08. For Halliday, the child has a notion of pastness, however rudimentary. For Gerhardt (1988), many children do refer to past occasions with no perceptual anchoring in the present situation. There have 
been numerous works that show how children can refer to past or future events around age two (see Behrens, 2001, for a review). There can be a considerable time lag between the first non-linguistic evidence that certain time concepts are available to the children (such as memory of past events) and their first production with linguistic means. Therefore, cognitive abilities might be more precocious than previously claimed, even before they are explicitly marked in language.

\subsubsection{Language-specific factors}

Time is a complex, abstract notion that is difficult to define in terms of objective experience or direct perception. Language seems to have a great impact on the children's capacity to comprehend and encode the unfurling of time. As Nelson (1996: 288) explains: 'the child alone cannot discover time, because (unlike concrete objects) it is not an entity that exists to be discovered. Rather, conceptions of process and change have led different societies to conceptualize time in different ways, and those ways are conveyed to children through language forms'.

But the kinds of temporal expressions available to children vary across languages. Language-specific learning of time concepts, just as for spatial concepts (Choi and Bowerman, 1985) has been demonstrated in a variety of studies for languages including Turkish (Aksu-Koç, 1988), German (Behrens, 2001), Polish (Smoczynska, 1995), and Inuktitut (Swift, 2004). 
These results are consistent with Slobin's (1991) work suggesting that the particular structures available in the languages children acquire may influence their perception of the world and their cognitive abilities.

\subsubsection{Impact of the input}

The linguistic systems acquired by children have been increasingly seen as being linked to the input, but many questions remain about the nature of the connection. To what extent can children's grammars be viewed as successive transitory systems with their own coherence (Cohen, 1924)? How exactly are they influenced by the frequency and saliency of the forms in the input (Tomasello, 2003)? Do children replicate the most frequent and salient forms they hear in the adult language addressed to them?

A number of studies of children's early productions have shown that early tense marking is closely linked to the Aktionsart of the verb ${ }^{2}$. One of the stronger claims was made by Wagner (1998: 86): 'children initially use present tense and/or imperfective morphology to mark atelicity and use past tense and/or perfective morphology to mark telicity'. However, Shirai and Andersen (1995) show that this preference might be due to the patterns children hear most in the language surrounding them and that they make prototypical associations between forms and functions that are linked to frequency in the input: telicity, for example, is associated with past events. Children then broaden the telic, punctual and resultative features to less

2 See Slobin, 1985, and Weist, 1986, for a summary and for the presentation of the 'Semantic Predisposition Hypothesis' and the 'Aspect before Tense hypothesis'. 
prototypical aspectual uses that are not produced as frequently in the input.

\subsection{Children's acquisition of the tense system in French}

According to previous studies on the acquisition of the tense system in French:

1) Around age two, children produce past participles with an adjectival value, such as cassé (broken) or pati (gone) (Sabeau-Jouannet, 1977). The situation is therefore present (speech time) and describes the result of an action.

2) Around 2;06 (i.e. two years and 6 months), they start marking aspectual differences between completed actions and ongoing activities. With the use of the 'passé composé', as in Jeannot a pris ma voiture (Jeannot took my car) or a fait poum (fell) (Grégoire, 1937), children still anchor their speech in the present situation (Meisel, 1985): past events are expressed through their impact on the present.

3) Around 3;00, children clearly mark anteriority and posteriority with the use of future tenses and past tenses. They introduce another reference point, for example with adverbs (Decroly and Degand, 1913). They localize events in the past. New uses of the 'passé composé' and the introduction of the 'imparfait' and the inflectional future (Morgenstern et al., 2009) mark a real dissociation between speech time and event time.

4) Around age four or five, children can position anteriority and 
posteriority relative to reference time and not only speech time. However, according to Labelle (1994), the use of the 'plus-que-parfait' at around age four is not sufficient proof that children rely on reference time that would be displaced from speech time. These first productions of the 'plus-que-parfait' do not express a different reference time but are anchored as perfective in the event time. The value of anteriority arrives later. For Sabeau-Jouannet (1977), the 'plus-que-parfait does not situate an event as anterior to the reference time already located in the past ${ }^{3}$. In fact, Fayol (1982) and Vandenplas-Holper (1975) even claim that some speakers can only achieve correct use of reference time (when different from speech time) at 19 years old.

One of the aims of our study is to work on recent spontaneous data that include phonetic transcriptions and are linked to the video, and to test whether, after coding the semantic values of the children's utterances as interpreted in context by their interlocutors, we find evidence for the successive stages described in the literature on the acquisition of French verbal morphology. We examine whether the order in which the children in our data produce the relevant forms is consistent across children, and whether the semantic values of their productions are correlated with their productive use of the conventional verbal forms.

\footnotetext{
${ }^{3}$ Our translation
} 


\subsection{Data and Method}

We used two of the datasets in the Paris corpus, Anaé and Madeleine, from $1 ; 06$ to $3 ; 03$. We coded only lexical verbs and did not code the verbs être (be) and avoir (have) even in their lexical uses, because these verbs, massively used as auxiliaries or as light verbs with low semantic value, would require a separate study and would bias the quantitative results. We created a coding system in an Excel file linked to the video with 1) the speaker, 2) the utterance produced, 3) situation type, 4) grammatical verbal form. 5) chronological time referred to (past, present and future, 6) marking of a displacement between speech time and event time (referred to as 'DISP' in the rest of the text). Since aspect is rarely marked as such in the oral French system and is difficult to grasp, we used this last category in order to distinguish between past events (coded as 'past') that have a connection with the present situation (impact, result, or clear association), and past events that are usually more remote and clearly disconnected from the present situation (they could for example have taken place in a different location), which were then coded as 'DISP'. Some of these six features required (inter)subjective evaluation of the child's communicative intent, especially since we could not rely on form. However, we do not attribute any knowledge to the children. Our work is based on the coders' 
interpretation of how they would react with the child at the moment the video was recorded. In other words, coders examined the ongoing discourse context, empathetically taking the perspective of the child's adult interlocutor, but producing their own interpretation. We used the adult's behavior as a coding clue. We limited our coding to focus on a few broad salient semantic distinctions that allowed good inter-coder reliability.

'Situation type' (which includes imperfective and perfective aspects) was coded using four main mutual exclusive dimensions: completed, ongoing, directive and potential. In rare cases that occurred only in the last recording, the code 'hypothetical' also had to be used. Situation type was coded in a very simplified way based on properties derived from the lexical aspect (verbal telicity, for example) and/or from the grammatical form. This approach was taken because it provided us with a complementary view to chronological time. 'Completed' corresponds to completed actions, while 'ongoing' is used for actions performed at the time of speaking, as well as for generic aspect since many cases were ambiguous. 'Directive' corresponds to demands or orders made by the children, 'potential' to any non-realized and not yet performed action. The distinction between directive and potential could be tricky to draw at times, where identifying directive situation type is especially subjective. Once again, this includes the lexical aspect of the verb (je veux - I want - led most often to 'directive' coding).

'Grammatical verbal form' corresponds to a description of the actual 
verbal morphological forms produced by the children, including any auxiliary or modal verb and even non-finite verb-forms. This allowed for coding of the following forms: present, imperative, past participle, 'passé composé', infinitive, preposition plus infinitive, modal plus infinitive, periphrastic future, imperfect and plus-que-parfait, conditional, inflectional future, gerund, subjunctive. It should be noted that coding of some of the grammatical verbal forms is heavily dependent on the adult interlocutor's interpretation and thus not independent of the other codes. For example, past participle and infinitive are often homophones in French; thus each production must be interpreted in context. The numerous cases of fillers (incomplete or imprecise production of the morphological markings) give rise to the same problems linked to contextual interpretations. Unclear situations (for example situations likely to call for a request for clarification from the adult) were coded as ambiguous.

'Time' was coded according to three dimensions: past, present, and future, although this represents a clear simplification of the linguistic system to refer to time. Talking about processes that are not directly located in the here and now is not impossible for children, but it is difficult to interpret this as such when children do not produce the complete grammatical forms. In 'j’ai tombé' (past: I fell), ‘je fais tomber' (present and causative: I make - it - fall), and 'je vais tomber' (future: I'm gonna fall), 'tombé/tomber' is pronounced in exactly the same way (/tõbع/). So if auxiliaries are omitted, 
and 'tombé/tomber' (past participle of the verb to fall, versus infinitive form) is the sole element produced by the child, coding the intended temporal relation, and its interpretation by the adult-interlocutor, can be problematic. To cope with this difficulty, it was necessary to rely on the extra-linguistic context and the most salient referent (concrete or abstract) of an utterance in deciding how to code the intended temporal meaning. For example, if the child said /tõbs/ in the immediate aftermath of an event in which some object had fallen, we coded 'past'. If the child was pushing some object simultaneously with the utterance, we coded 'present'. If the child (or somebody else) made something fall down a few seconds (or more) later, we coded 'future'. In those cases, the events would be coded as past and future without the 'DISP' component. Verbal forms were thus all coded as either past, present, future, or as non-interpretable. Following Smith (2004), reference to events that occurred prior to the time of utterance were coded as 'past', reference to events that had not yet occurred at the time of utterance was coded as 'future', reference to events or states in progress at the time of utterance was coded as 'present'. We also used the code 'present' for illocutionary language acts grounded in speech time. For example, je veux (I want) (commonly used alone in young French-speaking children) and je veux jouer (I want to play) were both coded as present even though in both cases the action referred to is hypothetical, because we considered the child's expressed intention to be present in chronological 
time.

We used the coding 'DISP' in order to study early markings of displacements between Speech Time and Event Time, that is, situations in which the action described is dissociated from the immediate context, typically because it occurs in a different location, takes place in the distant past or future, or is clearly hypothetical, as when Anaé, at the age of $3 ; 01$, recalls her last summer vacations and says to the observer 'Et moi j'ai allé sur le bateau' (And I went on the boat).

Table 1 gives an example of our coding.

Table 1

The data were coded by the two authors of the article. One session was fully coded separately by the two authors so as to allow measurement of inter-coder reliability. We used Cohen's kappa coefficient of reliability for the four codings: grammatical form, $\mathrm{k}=0.77$, chronological tense, $\mathrm{k}=0.45$, situation type, $\mathrm{k}=0.78$, and 'DISP', $\mathrm{k}=0.60$ (Cohen's kappa was measured using the 'irr' package of the R software). We looked at the reasons for disagreement and tried to achieve full agreement between the two coders. This resulted in a higher value of Cohen's kappa for chronological time, 0.71. To ensure reliability for the purpose of the current work, each child was first fully checked by the same coder, so that comparisons between sessions for the same child could be trusted, and a single coder finally controlled both children. 


\subsection{Overall Results}

We counted the codings in the two children's and the two mothers' productions of different forms according to the children's age. The results are summarized in the following tables.

All results are presented for the two children for two major periods (period 1 and period 2), each containing an equal number of sessions: Anaé's earlier period runs from $1 ; 06$ to $2 ; 00$ and her later period from $2 ; 01$ to $3 ; 01$, while Madeleine's go from $1 ; 06$ to $2 ; 01$ and from 2;02-3;01, respectively (see Tables 2 to 4 ). This division of the data provides a clear image of the production of the children in early development (when children are usually not considered to be able to express time) and in later development (when children are usually considered to start to express time correctly).

The results for the adults were computed on two sessions of Anaé's data and two sessions of Madeleine's data (one at the beginning and one at the end of the longitudinal data). There was no major difference between the two sessions used for each corpus. However, the productions of the two mothers were different one from the other (see below).

\subsubsection{Grammatical forms and tenses}

Table 2

As shown in Table 2, no less than 12 different morphological finite and non 
finite forms are available in the data. Composed forms ('passé composé', periphrastic future, modal + infinitive forms) are coded only once. We coded separately 'Preposition plus infinitive' forms, which correspond to a correct and frequent use of non-finite infinitive forms in French, and 'bare infinitive' forms (for example when Anaé at 2;00 says 'asseoir là' meaning 'I want to sit here'), which are not often found in the adult target language.

The most frequent forms are the present and imperative forms, which are the simplest verbal forms possible in French and are used more often by the adults than the children in our data.

The second most frequent forms are past participles and infinitives. For these two forms, a developmental trend was observed. Children produced more (usually ungrammatical) bare participles and bare infinitives during period 1. During period 2, the trend was opposite, with most participles and infinitives used in complex verbal forms. However, even the relatively low production rate of bare participles and infinitives by the adults is not yet matched by the children during the second period. The other grammatical modes and tenses (such as conditional, subjunctive, and even imperfect and inflectional future) are not productive before period 2. They are not frequent either in the adult data.

\subsubsection{Situation type}

Table 3

The results presented in Table 3 show that the two children's productions 
are once again very similar. The small differences between them (especially concerning potential situations) may reflect specific child or family style. However, for both children, the difference between period 1 and 2 is very small. It should be noted that, whatever the children's preferences, all situation types are used frequently. Ongoing situations are the most frequent for the two children. The two mothers display a slightly different global use, with no preference for ongoing situations but more forms referring to potential situations than the children, especially Madeleine's mother. Anaé's mother had few forms expressing completion, which was parallel to the low percentage of use of past references. Madeleine's mother's use of completion forms was similar to her daughter's. Differences in style were found in directive forms: Anaé's mother had more forms than her daughter, whereas the opposite was true for Madeleine.

\subsubsection{Temporal grounding}

Table 4

As shown in Table 4, the majority of uses across both children and adults refer to the present. The two children's references to time are very similar. In particular, there was no difference between the earlier and later periods for any temporal category for either child.

For both children, references to past or future events (as interpreted by the child's interlocutors and the coders and without making the distinction between 'DISP' past and future and 'non DISP' past and future) were 
relatively sparse but appeared very early. At age 1;06, Anaé produced 14 verbs, one of which was interpreted as referring to the past and one to the future. At the same age, Madeleine produced 27 verbs, two of which referred to past and four to future. From the very first session, the possibility of referring to past and to future was therefore present in both children, in similar percentages as a general trend. Anaé's mother produced few references to the past, much less than her daughter, whereas Madeleine's mother produced more references to the past than her daughter. However, reference to the future was similar between the two mothers, with more references than their daughters. Finally, references to the present were similar across all participants.

\subsubsection{Displacement}

Table 5

Table 5 presents the percentages of occurrences of displacement ('DISP') between Speech time and Event time against the total number of verbs produced. 'DISP' was rare in the first age range: 6 occurrences for Madeleine for 396 verbs produced and 2 for Anaé for 330 verbs produced. However, they were 10 times more frequent in the second age range for both children. For Anaé's mother, the frequency of 'DISP' values was similar to Anaé's, but in Madeleine's case, her mother used three times more forms with 'DISP' values. Madeleine's more frequent use may thus be explained 
by her input or the situation induced in the mother-child dialogue.

\section{ANALYSES AND DISCUSSION}

\subsection{Global trends}

The specificity of this study lies in the fact that our coding system enabled us to consider and relate four properties of Anaé and Madeleine's verbal systems between ages 1;06 and 3;00. Three of these properties (situation type, chronological time and 'DISP') are language functions produced by the children, as interpreted by the coders who took the perspective of the adult interlocutors. The fourth property is morphological, and categorizes the productions according to oral French grammar (grammatical verbal forms).

The results show a clear developmental trend in the forms used in the verbal system, which are consistent with our previous results on future tenses (Morgenstern et al. 2009). At the beginning of the data and until around $2 ; 00$, the two children mostly produce forms corresponding to the most frequent forms in the input. These forms are often used quite 'bare', without their usual accompanying grammatical markers, such as auxiliaries and clitics. After 2;00, the children start to produce a much larger and more complete variety of forms, including imperfect, future, and conditional. They also produce a greater range of grammatical markers, which result in different codings of the grammatical categories of some of their verbal productions: from past participle to 'passé composé' (from tombé /fallen to 
il est tombé / he has fallen), from infinitive to preposition plus infinitive (from sauter / jump, to c'est pour sauter / it's to jump), or modal plus infinitive (je veux sauter / I want to jump) and periphrastic future (je vais sauter / I'm going to jump).

By $2 ; 01$ and 2;02, the children are already producing long utterances, with both Anaé and Madeleine having an MLU of at least 2.8 by age 2;00. It is interesting to note that the children's verbal forms can be categorized into three classes on the basis of child production frequency: a highly frequent category (between 50 and 80\%) which contains present and imperative forms, a moderately frequent category (between 10 and 25\%) which contains all verbal constructions built around the infinitive and past participle forms (which are often homophones in French), and an infrequent category (less than 5\%) which contains future, imperfect, conditional, and subjunctive.

Despite those salient developmental differences in the verbal forms, two of the properties describing the functions of language (situation type and time) did not seem to change much over age. The children produced language that was distributed over all possible functions. All the categories of situation types in our coding system could be found from the first session on. Although the number of verbs produced increased tenfold between age $1 ; 06$ and about age $2 ; 04$, the percentages of the various situation types were very similar. 
References to the chronological present were the most frequent (see Table 4), which is in keeping with traditional results about the deictic quality of children's speech, but the children nonetheless often referred to past and future events, at least from the interlocutor's point of view. This was true for the recordings in period 1 as well as for the recordings in period 2.

The final property studied, 'DISP', appeared infrequently and only in the recordings after age 2;00. This means that the children clearly spoke about elements that were not connected to the here and now only when they also started to produce a lot of complex grammatical forms.

Our overall results could be interpreted in favor of a kind of dissociation between the use and mastery of functions and forms by children. Through their first verbal productions, the two little girls displayed what was interpreted by their interlocutors as a wide range of language functions. In other words, their interaction with the adults provided ample pragmatic support for them to develop and deploy those various communicative functions. So why did they take so long to produce the whole range of conventionalized forms (imperfect, conditional, subjunctive, inflectional future, etc.) corresponding to these functions in the French grammatical system?

One possible explanation is simply that the children had not yet in fact mastered these functions - that their adult interlocutors might simply 
understand or interpret early productions as having these functions even if they are not intended by the children. However, this hypothesis seems to be in contradiction with the children's obvious ease in their interaction with their mothers and the rare cases of apparent misunderstanding.

One of the problems we encounter in analyzing or interpreting language functions is that they are internalized constructs that cannot be directly transmitted between interlocutors. Usually, speakers have to rely on some external element, such as a word, gesture, body language, deictically indicated objects, or on shared knowledge, to convey function and meaning. Moreover, even with an external element, there is no guarantee that the function assigned by one interlocutor will be similar or even close to the function assigned by another interlocutor. Our results show that children do not pair form and function as well as adults at the beginning of the developmental process. Shared functions might be attained only after a certain amount of experience, perhaps only once the internal representation of the function has stabilized and evolved based on the successful or unsuccessful interactions of the child with her environment and her interlocutors.

Another explanation for the late production of linguistic forms would be that real mastery of the functions marked linguistically by tense and aspect morphology does not take place before the forms actually appear. Without forms through which to share knowledge, it is difficult for the adult 
and the child to build and develop common language functions. This was clear in the problems we encountered with our semantic coding, and during the coding process we needed to redefine a common basis to code the functions consistently. In a similar way, adults and children have to build meaning together. On the basis of language forms (the visible parts), they must co-construct the language functions (the hidden parts) that might correspond to them. This is clear in the 'DISP' situations for which specific language forms occur in the children's speech, especially adverbs, prepositional noun phrases, or reference to specific elements in the interaction scene. To illustrate this point, in the sections below, we present analyses of the uses of 'DISP' by the two children.

\subsection{Analyses of verbal productions coded as 'DISP'}

The first five 'DISP' examples in Madeleine's productions are instructive because they increase nicely in complexity and in distance to Speech Time.

(2) Madeleine, 1;09

CHI: [ə] parti [a] bus. [/a/ gone /a/ bus]

(3) Madeleine, 1;09

CHI: dormir. [sleep]

Both examples are from storytelling contexts in which Madeleine, who probably knows the story very well, describes the pictures in the book. It was difficult to determine whether she was talking about a result or a past 
event, and in fact the coders disagreed about whether the 'DISP' criteria were met (i.e. they are ambiguous examples). What made those examples possible 'DISP' occurrences was that in the first case the page where the 'bus action' was depicted was being turned. In the second case, Madeleine was pointing at a picture of a puppet waking up, although there was also an image of the same puppet sleeping, on the left page. So in both cases, however tentative this interpretation might be, Madeleine could be viewed as referring to some past event disconnected from the present within the process of storytelling.

(4) Madeleine, 1;11: MOT and CHI are reading a book.

CHI: est passé le train. [*went by the train*.]

MOT: est passé le train? ah ben non, y'a pas d' train là. [*went by the train*? no there is no train here.]

In this other situation of storytelling, Madeleine refers to something that does not belong to the story, as attested by the mother's reaction. So there is a clear discontinuity between what Madeleine says and what is happening in the here and now. Whether Madeleine talks about the past, the future or a hypothetical situation is unknown because there is no clear temporal marking.

(5) Madeleine, 2;01: Madeleine is using a toy telephone, 'talks to her sister' who is in school and hangs up.

MOT: elle était où Marie, Madeleine? [where was Marie, Madeleine?] 
CHI: est au collège. [is in school.]

MOT: au collège? [in school ?]

CHI: oui. [yes.]

MOT: elle t'a téléphoné? [she called you?]

CHI: oui. [yes.]

MOT: elle rentre? [she's coming back?]

CHI: elle rentre ce soir. [she's coming back tonight.]

MOT: ce soir? à quelle heure? [tonight? at what time?]

CHI: euh et demi. [uhh *half past*.]

In this example, Madeleine is in a situation of pretend play with a fake telephone. Her use of the present tense when she says elle rentre ce soir to her mother echoes her mother's utterance elle rentre and encodes the fact that her sister comes home every day from school in the evening, but she is indeed referring to the chronological future.

(6) Madeleine, 2;01

MOT : pourquoi as-tu peur de l'escalier? [why are you afraid of the staircase ?]

CHI : un jour l'est tombé dans l'escalier et de mon lit. [one day * she fell* off the stairs and off my bed.]

MOT (to OBS) : oui parce que deux jours après elle est tombée de son

lit. [yes, because two days later she fell off her bed.]

In this final example, Madeleine is clearly telling a story about herself. She 
is still mixing things a little bit, since she is talking about the stairs and the bed in a slightly a-grammatical construction (the two terms of the 'et' construction are not parallel), and she is using the wrong personal pronoun (the reduced /1/ production is used by adults to refer to the third person but she should have used the first person to talk about herself). Nonetheless, this is a very complex and quite thoughtful speech for a child aged 2;01.

What is remarkable is that in the first four 'DISP' productions analyzed above - examples (2) to (5) -, the context is storytelling: first by the mother, then by Madeleine herself. It is also interesting to note that in the clear-cut 'DISP' examples (the two final ones), Madeleine uses a temporal expression outside the verb ('ce soir' and 'un jour'). Finally, in these last two examples, Madeleine uses two plurifunctional markers, the present tense (example 5) refers to the future and not the present and the 'passé composé' (example 6) refers to the distant past. So it seems that Madeleine's learning of 'DISP' is grounded in storytelling, which is an ideal situational context for learning about dissociation from Speech Time. At first (examples 2 and 3), the temporal distance is very short, so the elements Madeleine speaks about are probably still in her working memory, or perhaps her 'visual sketchpad' (see Baddeley, 2003) since she is reading books with her mother. These examples are therefore at best proto-'DISP' situations. But such situations help her to learn to distance herself from the here and now, which she does in an unusual and surprising way in example (4). At that point, she seems 
aware that it is possible to refer to something absent and that this is usual in storytelling.

In example (5), the situation is repeated, but with two important differences: she is no longer in a book-reading activity but rather is talking about something real (her sister's coming home). To do so, she uses a temporal expression 'ce soir' (this evening) that marks exactly what she is talking about, and the time to which she is referring. These markers provide a way of distancing the event from the here and now without using tenses such as the future or the imperfect, which the child does not produce yet (Madeleine's first future and imperfect verb forms will appear during the next session, at age $2 ; 02$ ). Note that example (5) is probably reproduced from adults' previous speech in similar situations. But this is not the case in example (6), which is non-adult in its form but contains all the elements ('un jour' [one day] associated to the 'passé composé') that allowed the coders to identify it as 'DISP': it has a clear temporal reference, a clear situation, and it is an auto-biographical narrative. The fact that Madeleine clearly constructs the utterance herself shows that she is in the process of mastering the uses of 'DISP' situations. In the next session, she will once again produce 'DISP' utterances within storytelling but using inflectional future and 'imparfait' tenses. By age 2;04, she starts producing a lot of 'DISP' utterances.

Anaé's first uses of 'DISP' are also very interesting, especially because 
they appear in a different setting than Madeleine's, which shows that storytelling situations, as produced by Madeleine, are but one type of situations where 'DISP' can be produced. For Anaé, the first recurring situations are not storytelling ones, but when talking about 'what actually happened' with verbal stimulation from her mother. For example:

(7) Anaé, 2;02 (Omer, the family dog has wrecked a stone wall in the garden.)

*MOT: il a encore mangé le mur. [he ate the wall again.]

*OBS: mangé le mur ! [ate the wall !]

*MOT: <hum hum $>$. [uhh - nodding and smiling.]

*CHI: l'a mangé [lə] mur. [(he) ate the wall.]

In this example, Anaé follows her mother's prompt, repeating a part of what her mother has said before. But during the same session, she was able to answer her mother's (simpler) questions by herself. She is thus able to do more than replicate the adults' language, but her use of 'DISP' is still very uncertain. Her borrowings from the preceding adult productions continue in the rest of our recordings, but she replicates the adults' utterances less and less and she produces one utterance, coded as 'DISP', of her own initiative in our data:

(8) Anaé, 3;01

CHI: on a trouvé, hier on a trouvé peut-être. [we found yesterday, we found maybe.] 
In this example Anaé is talking about something that she did before playing with the toy she is manipulating in the situation. Whether she is talking about a real fact is not important here, but she uses 'hier' (yesterday) to locate her actions in time. Without this indication, there would have been no clue that this puzzling utterance should be coded as 'DISP'. This emphasizes the role of explicit linguistic elements: without grammatical elements (such as temporal adverbs), we cannot easily interpret Anaé's ability to refer to displaced time, outside well-formatted situations.

At first glance, the story of the emergence of 'DISP' is very different from the one about time and situation types described in Section 3.1. We first explained how we frequently encountered situations in which the children produced words that could be interpreted as expressing time and various situation types. The regularity of these situations suggested to us that children might express these features without using the corresponding conventional language forms. It is much more difficult, however, to identify the 'DISP' value - actual displacement and lack of anchoring in the present situation - with certainty. The occurrences are much less frequent, and only the specific properties of the ongoing situation (story-telling, eating a meal, playing a specific game) allow the adult to resolve the intended referent and identify it as clearly displaced from speech time. When those properties are insufficient, the identification of a 'DISP' value depends on the presence of explicit linguistic marking in discourse, as shown in example (8). The child 
uses the 'imparfait' with the nonstandard form 'était bougé' (for 'avait bougé', it had moved, using the auxiliary be instead of have), but it is also thanks to the semantic frame induced by the word 'caddy' (trolley) that the observer can reconstruct the reference to what happened in the supermarket.

(8) Anaé, 2;08

CHI: euh le caddy il était bougé aussi. [so the trolley *was* moved too.]

OBS: le quoi? [the what?]

CHI: euh, le caddy de moi, il était bougé. [the caddy *of me**was* moved.]

OBS: t'es allé au supermarché aujourd'hui? [you've been to the supermarket today?]

Such marking in both parent and child speech may be the crucial clues that allow the children to learn to express displacement from the here and now, in a cognitive co-construction process grounded in discourse.

The data we have presented thus underlines how children's productions are interpreted in context as referring to complex events and a variety of temporal realities and situation types from very early on. Linguistic forms are not always produced and indeed not required. But in some cases, especially when shared knowledge is insufficient, explicit markers become necessary. Our interpretation is that they are perceived as reliable cues because they are useful, especially in broader social contexts 
than the family environment, with less shared knowledge and familiarity.

\section{CONCLUSIONS}

We have shown that, as predicted in the literature, French children start to produce present/imperative forms, closely followed by 'passé composé' and periphrastic future forms, with gradual progress in the production of the actual morphosyntactic marking. It is only later (in our study after age 2;00) that they start to produce less frequent forms, such as 'imparfait' and future. The relative infrequency of linguistic forms for expressing displacement from speech time is consistent with most previous research, which proposes that children mark aspect before tense and are restricted to referring to the here and now.

Our coding of other features however, suggests a different story. Children appear to be able to refer to past, present, future, and to different aspectual meanings, from quite an early age, but in order to observe this, it is necessary to go beyond language forms and to give attention to communicative meaning. Culioli (2000:25) describes children's productions in the following way: 'the system seems poorer on the surface, but contains virtual elements that will progressively become overt markers'4. Interestingly enough, detecting these 'virtual elements' seems to be what their interlocutors actually do, and it probably helps the children in the

${ }^{4}$ Our translation. 
language developmental process. Our proposal is that functions appear first, or are interpreted by the interlocutors before the development of conventional forms. Our analysis of the 'DISP' value also underlines the role of narrative and non-shared knowledge in communication (Nelson, 1996). Thus, full understanding of language development calls for usagebased pragmatics and semantics as well as usage-based syntax (see also Rossi and Parisse, this volume). It takes a certain amount of experience for children to use the forms borrowed from their input productively. When the value of explicit grammatical marking becomes clear to them, the children can achieve more confident agreement about meaning and function with their interlocutors. But even after children begin to produce clear grammatical forms, we must keep in mind the fact that it does not guarantee that they have the same form/function mappings as their interlocutor. Gradual co-adjustment is needed between children and adults for meaning to be co-constructed in discourse. But of course, this process continues at various degrees, in all types of interactional contexts, and at all ages.

\section{ACKNOWLEDGEMENTS}

This work was supported by a grant from the Agence Nationale pour la Recherche, France. We would like to thank Nancy Chang for insightful comments, suggestions and thorough editing of this paper, Martine Sekali for her enormous work as editor of this special issue and the CoLaJE team 
for all their feed-back during the research process. We are very grateful to our three anonymous reviewers for their constructive comments and tried to follow their suggestions. Any errors and other shortcomings are, of course, our own responsibility.

\section{REFERENCES}

Aksu-Koç, A. (1988). The acquisition of aspect and modality: the case of past reference in Turkish. Cambridge: Cambridge University Press.

Applebee, A. N. (1978). The child's concept of story: Ages two to seventeen. Chicago: University of Chicago Press.

Baddeley, A. (2003). Working memory and language: an overview. Journal of Communication Disorders, 36(3): 189-208.

Behrens H. (2001). Cognitive-conceptual development and the acquisition of grammatical morphemes: the development of time concepts and verb tense, In: M. Bowerman and S. C. Levinson (eds.), Language acquisition and conceptual development. Cambridge: Cambridge University Press, pp. 450-474.

Bronckart J.-P., and Sinclair, H. (1973), Time, tense and aspect. Cognition, 2: $107-130$.

Choi, S. and Bowerman, M. (1991). Learning to express motion events in English and Korean: the influence of language-specific lexicalization 
patterns. Cognition, 41: 83-121.

Cohen, M. (1924). Sur les langages successifs de l'enfant, in Mélanges linguistiques offerts à M. J. Vendryes par ses amis et ses élèves, Paris, E. Champion, collection publiée par la socité de linguistique, XVII, 109127.

Cromer, R. F. (1968). The development of temporal reference during the acquisition of language. Unpublished doctoral dissertation, Harvard University.

Culioli, A. (2000). Pour une linguistique de l'énonciation. Tome 1. Paris : Ophrys.

Decroly, O., and Degand, J. (1913). Observations relatives au développement de la notion du temps chez une petite fille, Archives de psychologie, vol. XIII, 50: 113-161.

Fayol, M. (1982). Le plus que parfait. Etude génétique en compréhension et production chez l'enfant de quatre à dix ans, Archives de psychologie, 50: 113-161.

Ferreiro, E. (1971), Les relations temporelles dans le langage de l'enfant. Genève: Droz.

Gerhardt, J. (1988). From discourse to semantics: The development of verb morphology and forms of self-reference in the speech or a two year old. Journal of Child Language, 15: 337-394.

Halliday, M. A. K. (1975). Learning how to mean: Explorations in the 
development of language. New York: Elsevier.

Klein, W. (1992). The present perfect puzzle. Language, 68: 525-552.

Labelle, M. (1994). L'utilisation de la valeur des temps du passé par les enfants francophones. Revue Québécoise de linguistique, 23/1: 99-121.

Meisel, J. (1985). Les phases initiales du développement de notions temporelles, aspectuelles et de modes d'action. Etude basée sur le langage d'enfants bilingues français-allemand, Lingua, 66: 321-374.

Morgenstern, A., Parisse, C., and Sekali, M. (2009). A la source du futur : premières formes verbales dans les productions spontanées de deux enfants français de 18 mois à 3 ans. Faits de Langues: Le futur, 33 :163175.

Nelson, K. (1996). Language in cognitive development. Cambridge: Cambridge University Press.

Reichenbach, H. (1947). Elements of symbolic logic, Berkeley: University of California Press.

Rossi, C. and Parisse, C. (2012) Categories in the making. Journal of French Language Studies (this issue), Cambridge: Cambridge University Press.

Sabeau-Jouannet, E. (1977). L'expression de l'organisation spatiale et temporelle, son évolution chez l'enfant de 2 à 5 ans, In : F. François, D. François, E. Sabeau-Jouannet and M. Sourdot (eds.), La syntaxe de l'enfant avant 5 ans, Paris : Larousse, pp. 193-204. 
Shirai ,Y., and Andersen R. W. (1995). The acquisition of tense-aspect morphology: a prototype account. Language 71: 743-762.

Slobin, D. (1991). Learning to think for speaking: native language, cognition and rhetorical style. Pragmatics 1: 7-25.

Slobin, D. (1985). Crosslinguistic evidence for the Language-Making Capacity. In: D. I. Slobin (ed.). The crosslinguistic study of language acquisition, Vol. 2: Theoretical issues. Hillsdale, NJ: Lawrence Erlbaum, pp. 1157-1249.

Smith, C. S. (1980). The acquisition of Time Talk: relation between child and adult grammar. Journal of Child Language, 7: 263-278.

Smoczynska, M. (1995). The acquisition of Polish verb morphology. Paper presented at the Colloquium on Developmental Psychology, University of California, Berkeley.

Swift, M. (2004). Time in child Inuktitut: a developmental study of an Eskimo-Aleut language. Berlin/New-York: Mouton de Gruyter.

Tomasello, M. (2003). Constructing a language, a usage-based theory of language acquisition, Cambridge, M.A.: Harvard University Press.

Vandenplas-Holper, C. (1975). La compréhension d'expressions verbales de la succession temporelle par des enfants de 6 à 11 ans, Revue française de pédagogie, 31: 4-15.

Wagner, L. (1998). Children's Developing Knowledge of Tense and Aspect. Paper presented at NECSS graduate student Cognitive Science forum, Cornell University. 
Weist, R. M. (1986). Tense and aspect: temporal systems in child language. In: P. Fletcher and M. Garman (eds.), Language acquisition, $2^{\text {nd }}$ edition. Cambridge: Cambridge University Press, pp. 356-374.

Weist, R.M., Wysocka, H. and Lyytinen P. (1991). A cross-linguistic perspective on the development of temporal system, Journal of Child Language, 18: 67-92.

Total number of words: 8588

Revised manuscript: August 24, 2011 


\begin{tabular}{|c|c|c|c|c|c|c|c|c|}
\hline session & line & $\begin{array}{l}\text { speake } \\
r\end{array}$ & Utterance & form & Time & Aspect & $\begin{array}{l}\text { Gram verbal } \\
\text { form }\end{array}$ & DISP \\
\hline $\begin{array}{l}\text { Mad- } \\
1 \_11\end{array}$ & 951 & CHI & $\begin{array}{l}\text { l'a perdu sa maman } \\
\text { [lost her mummy] }\end{array}$ & $\begin{array}{l}\text { a } \\
\text { perdu }\end{array}$ & past & completed & $\begin{array}{l}\text { passé } \\
\text { composé }\end{array}$ & no \\
\hline $\begin{array}{l}\text { Mad- } \\
2 \_06\end{array}$ & 1056 & $\mathrm{CHI}$ & attends. [wait] & attends & present & directive & imperative & no \\
\hline $\begin{array}{l}\text { Mad- } \\
\text { 2_06 }\end{array}$ & 1144 & CHI & $\begin{array}{l}\text { elle montre la } \\
\text { grenouille. [she shows } \\
\text { the frog] }\end{array}$ & montre & present & ongoing & présent & no \\
\hline $\begin{array}{l}\text { Mad- } \\
2 \_06\end{array}$ & 1669 & CHI & $\begin{array}{l}\text { et on a pas trouvé des } \\
\text { plus petits pour moi } \\
\text { [and we didn't find } \\
\text { smaller models for me] }\end{array}$ & $\begin{array}{l}\text { a pas } \\
\text { trouvé }\end{array}$ & past & completed & $\begin{array}{l}\text { passé } \\
\text { composé }\end{array}$ & yes \\
\hline $\begin{array}{l}\text { Mad- } \\
\text { 2_06 }\end{array}$ & 4011 & CHI & $\begin{array}{l}\text { maintenant on fait la } \\
\text { galipette [now we jump } \\
\text { up and down] }\end{array}$ & fait & future & directive & présent & no \\
\hline $\begin{array}{l}\text { Mad- } \\
2 \_11\end{array}$ & 4280 & CHI & $\begin{array}{l}\text { on lui dira quand ce sera } \\
\text { plus un secret [we'll tell } \\
\text { her when this will no } \\
\text { longer be a secret] }\end{array}$ & dira & future & potential & inflect fut & yes \\
\hline
\end{tabular}

Table 1: Extract from the coding grid. 


\begin{tabular}{l|cc|cc|c|c} 
& \multicolumn{3}{|c|}{ Anaé } & \multicolumn{2}{c|}{ Madeleine } & \multicolumn{2}{c}{ Adults } \\
& $1 ; 06-2 ; 00$ & $2 ; 01-3 ; 01$ & $1 ; 06-2 ; 01$ & $2 ; 02-3 ; 01$ & Anaé & Madeleine \\
\hline present or imperative & 48.9 & 63.1 & 56.6 & 61.0 & 77.9 & 58.3 \\
past participle & 6.3 & 3.9 & 16.4 & 1.0 & 0.1 & 0.5 \\
passé composé & 15.7 & 10.0 & 4.8 & 8.1 & 1.2 & 11.7 \\
infinitive & 15.0 & 3.4 & 16.9 & 2.0 & 0.5 & 0.2 \\
prep+infinitive & 0.9 & 1.0 & 3.0 & 4.3 & 2.2 & 4.8 \\
modal+infinitive & 4.4 & 9.7 & 1.3 & 10.8 & 4.5 & 10.0 \\
periphrastic future & 8.5 & 7.0 & 0.8 & 9.7 & 9.2 & 3.8 \\
imparfait + plus que & 0.0 & 0.8 & 0.0 & 1.6 & 1.1 & 5.3 \\
parfait & 0.0 & 0.2 & 0.3 & 0.4 & 0.3 & 2.4 \\
conditional & 0.0 & 1.0 & 0.0 & 0.6 & 1.8 & 1.2 \\
inflectional future & 0.0 & 0.0 & 0.0 & 0.1 & 0.4 & 0.0 \\
gerund & 0.3 & 0.0 & 0.0 & 0.4 & 0.7 & 1.7 \\
subjunctive & & & &
\end{tabular}

Table 2: Percentages of production of grammatical verbal forms 


\begin{tabular}{ll|cccc} 
& & completed & directive & ongoing & potential \\
\hline \multirow{2}{*}{ Anaé } & $1 ; 06-2 ; 00$ & 22 & 23 & 32 & 22 \\
& $2 ; 01-3 ; 00$ & 16 & 25 & 38 & 21 \\
\hline \multirow{2}{*}{ Madeleine } & $1 ; 06-2 ; 01$ & 19 & 31 & 42 & 8 \\
& $2 ; 02-3 ; 01$ & 13 & 26 & 49 & 11 \\
\hline \multirow{2}{*}{ Adults } & Anaé & 3 & 36 & 31 & 30 \\
\cline { 2 - 6 } & Madeleine & 18 & 19 & 40 & 23
\end{tabular}

Table 3: Percentages of use of 'situation type' 


\begin{tabular}{ll|ccc} 
& & past & present & future \\
\hline \multirow{2}{*}{ Anaé } & $1 ; 06-2 ; 00$ & 16 & 78 & 6 \\
& $2 ; 01-3 ; 01$ & 13 & 80 & 7 \\
\hline \multirow{2}{*}{ Madeleine } & $1 ; 06-2 ; 01$ & 16 & 78 & 7 \\
& $2 ; 02-3 ; 01$ & 8 & 85 & 7 \\
\hline \multirow{2}{*}{ Adults } & Anaé & 3 & 84 & 13 \\
\cline { 2 - 5 } & Madeleine & 21 & 69 & 10
\end{tabular}

Table 4: Percentages of reference to time 


\begin{tabular}{l|cc|cc|cc} 
& \multicolumn{2}{|c|}{ Anaé } & \multicolumn{2}{c|}{ Madeleine } & \multicolumn{2}{c}{ Adults } \\
\hline \multirow{2}{*}{ Age } & $1 ; 06-$ & $2 ; 01-$ & $1 ; 06-$ & $2 ; 02-$ & Anaé & Madeleine \\
DISP & $2 ; 00$ & $3 ; 01$ & $2 ; 01$ & $3 ; 01$ & 2 & 14
\end{tabular}

Table 5: Percentages of use of 'DISP' 